\title{
Management of sustainable development of territories through the reproduction structure of large investment construction projects
}

\author{
Elena Stupnikova $^{1^{*}}$, and Tatyana Sukhadolets ${ }^{2}$ \\ ${ }^{1}$ Russian University of Transport (MIIT), ObrazcovaUlitsa, 9b9, 127994 Moscow, Russia \\ ${ }^{2}$ LLC "Global Innovations", Krutitskaya nab., 25-3, 115088 Moscow, Russia
}

\begin{abstract}
The infrastructure spatial planning is at the heart of modern sustainable development issues. The methods for selecting an infrastructure project for construction are an important conceptual basis for sustainable development, which provide effective assistance to the development of territories. The study is aimed at finding and analyzing existing approaches and tools for assessing territorial development in the reproductive structure of the economy, as well as developing a methodological and procedural assessment of large infrastructure projects to solve socio-economic problems. The methods of analysis of causes and effects, as well as methods of investment planning are used. At the same time, according to the authors, the main conceptual and methodological prerequisite that distinguishes the proposed approach should take into account the effects of intersectoral interaction. It is necessary to assess the contribution to the sustainable development of territories "with a project" and "without a project".
\end{abstract}

\section{Introduction}

The sustainable ways of developing infrastructure are a major concern at levels of government. The choice of methodological approaches to assessing indicators of sustainability criteria for infrastructure investment projects is especially difficult in large construction projects.

The classical theory of infrastructure location emphasizes the role of transport costs as a determining factor in economic activity [1]. The new economic geography, which is associated with the globalization of industries, the speed of movement of labor, also emphasizes the role of transport costs as a factor of location in the context of imperfect competition and varying degrees of interregional labor mobility [2]. The macroeconomic theory of endogenous growth has developed a framework in which transport infrastructure can be identified as a source of economic growth through its contribution to technological change [3]

Along with reducing transport costs, improving transport infrastructure leads to a decrease in the production costs of firms and, consequently, to an increase in the

\footnotetext{
* Corresponding author: stupnikovaea@ya.ru
} 
productivity of factors of production [4]. In addition, lower production and distribution costs caused by good transport links can also lead to economies of scale and increased competition, which in turn lead to higher overall productivity levels through natural selection in favor of more productive firms [5].

Another important contribution of transport to economic productivity relates to what is commonly referred to in the literature as the "agglomeration effect" caused by transport [6]. The agglomeration effect (agglomeration economy) occurs when economic agents (enterprises, employees) receive significant benefits from proximity to other economic agents.

Improvements in transport infrastructure can increase the resilience of agglomeration economies to the extent that they increase connectivity within the spatial economy. By changing the way people and firms have access to economic activity, transport affects the implementation of external factors of agglomeration and, therefore, its impact on productivity [7].

From all that has been said, a hypothesis can be formulated that investments in transport infrastructure bring significant economic benefits and contribute to economic growth, firstly, justifying public funding, and secondly, improving transport infrastructure and increasing population mobility and production productivity.

Most often, large-scale investments in transport infrastructure have traditionally been estimated under the assumption of equivalence between direct and indirect economic effects [8], which, in our opinion, is correct only in the general case. Despite common practice, there is still no consensus among economists on the definition of revenues and costs in large infrastructure transport projects. Discussions are needed, for example, of the Moscow-Kazan high-speed rail (HSR), this illustrates: with the approved project and planned investments, a decision was made to build a new Moscow-Kazan HSR.

There are disputes about the influence of direct users of infrastructure (indirect consequences) and factors [9] that have a beneficial effect on the long-term dynamics of the gross domestic product (GDP) [10], and the effects associated with the location of certain industries (strategic effects) [11].

The relationship between the transport system and the rest of the economy has been widely discussed in the economic literature recently $[12,13]$. The infrastructure improvements at the aggregate level are compared to the improvements that occur in the transportation system itself. D. Aschauer [14] began intensive research on the empirical level about the elasticity of total output in relation to public capital in the construction of transport infrastructure. The key role is given to the "basic infrastructure": roads, ports, railways, which are the main components. But when elasticities of demand are used to calculate social capital: rates of return, excess of expenditures in relation to private capital income, this is explained as reflecting the aggregate effects of general equilibrium [15].

The impact of investment transport costs leads to spatial economic development. The theory began with Krugman (1991) [16]. Krugman assigned transport costs a central role in the development of the economy through the influence on workers, trade flows and regional income.

Some recent papers have used these theoretical developments, which are called new economic geography (NEG), taking into account the general economic benefits of improving transport infrastructure [17]. The consequences of improving transport infrastructure were analyzed together with spatial development [18].

Thus, we note that the significance of the impact of transport construction investments described in the literature is much more complex than it might seem at first glance. Definitions of investment efficiency in the implementation of construction transport projects should give transport costs a more complex role in the economy, compared to the traditional role of development (prices, productivity, etc.). 
The samuelson's classic models emphasized industrial specialization and were widely used in earlier literature. Later, in spatial general equilibrium models (for example, RAEM [19]), in addition to transport, the influence of transport investments on the labor market and the housing market is studied. Models of interdependence of production, consumption and transport are being developed to assess the impact of transport infrastructure. The models differ in geographic coverage (number of regions) and the number of sectors of the economy that are affected by transport construction. These models usually show the impact on prices and income [18], environment, demography [21], economy [22], society, technology [23] and even politics [24].

It can be concluded that the transport system itself is subject to the influence of these dynamic influencing factors and has an opposite effect on some of these factors. Transport investments can relate to different elements of influence, such as renewing the car fleet, improving logistics services, or new rail lines. It also suggests that investments should have an impact on the travel markets, transport services.

Thus, through changes in key market variables, a new equilibrium is established in the transport system. Changes in one of the markets lead to changes in the productivity of the transport system as a whole.

\section{Materials and methods for choosing technical and economic indicators}

When assessing the technical and economic indicators of investment projects, cash flows are most often analyzed, and their change depending on the market situation, changes in the macroeconomic situation, etc. Methods for assessing large construction projects in which the state participates, present an algorithm for the formation of a construction project quality index. So, for example, the algorithm for forming the quality index of the transport infrastructure of railway transport takes into account the dynamics of the length of the railway track sections with excess tonnage passed through, or the service life. When assessing the quality of the road transport infrastructure, the dynamics of indicators is taken into account: the share of federal, regional, or inter-municipal roads; the length of federal, regional or inter-municipal roads; the share of highways serving traffic in congestion mode [25].

According to the approved methodology for assessing the socio-economic effects of construction (reconstruction) and operation of transport infrastructure projects, "the final assessment indicators are:

A. Calculation of the increase in Gross Value Added as a result of the implementation of the infrastructure project;

B. Calculation of tax and other obligatory payments to the budgets of the budgetary system of Russian Federation in the implementation of an infrastructure project;

B. Calculation of the monetized effect of saving time on the way of passengers and goods during the implementation of an infrastructure project;

C. Calculation of the monetized effect of increasing the safety of passenger and cargo transportation;

D. Calculation of the monetized agglomeration effect of the implementation of the infrastructure project;

E. Calculation of the monetized effect of the increase in the output of goods (works, services) as a result of the elimination of infrastructure restrictions

G. Calculation of the increase in Gross Domestic Product of Russian Federation in connection with the implementation of the infrastructure project.

$\mathrm{H}$. Calculation of budgetary effects from the implementation of an infrastructure project. 
The increase in Gross Value Added (GVA) as a result of the implementation of the infrastructure project is calculated in the prices of the base year, this is the previous one for the accounting year, and is determined by the formula:

$$
G V A=G V A 1+G V A 2
$$

where:

$\mathrm{GVA}_{1}$ - the increase in gross value added at the investment stage of the infrastructure project in base year prices;

$\mathrm{GVA}_{2}$ - the increase in gross value added at the operational stage of the infrastructure project in base year prices.

The increase in gross value added at the investment and operational stage of the infrastructure project in base year prices is determined by the formula:

$$
G V A=\sum_{t=a}^{T} \frac{G V A^{t}}{(1+r b)^{\left(t-n+0^{5}\right)}}
$$

where:

$\mathrm{T}$ - the last year of the infrastructure project implementation;

$\mathrm{t}$ - calendar year of the infrastructure project implementation, $\mathrm{t} €[\mathrm{a} ; \mathrm{T}]$;

a - first year of the infrastructure project implementation.

GVA - the increase in gross value added at the investment stage of an infrastructure project in year t;

$\mathrm{rb}$ - discount rate;

$\mathrm{n}$ - base year;

0.5 - an adjustment value that provides the distribution of discounted cash flows throughout the year.

The monetized agglomeration effect (MEA) of the implementation of an infrastructure construction project at base year prices is determined by the formula [23]:

$$
M E A=\sum_{t=a}^{T} \frac{M E A^{t}}{(1+r b)^{\left(t-n+0^{5}\right)}}
$$

where:

$\mathrm{T}$ - the last year of the infrastructure project implementation;

$\mathrm{t}$ - calendar year of the infrastructure project implementation, $\mathrm{t} €[\mathrm{a} ; \mathrm{T}]$;

a - the first year of the infrastructure project implementation;

MEA - the monetized agglomeration effect of the implementation of the infrastructure project in year $\mathrm{t}$;

$\mathrm{rb}$ - discount rate;

$\mathrm{n}$ - base year;

0.5 - an adjustment value that ensures the distribution of discounted cash flows throughout the year.

Thus, methods for assessing infrastructure projects have been developed, according to which project initiators must submit their project for consideration by the state. The large construction projects always require significant amounts of funding. However, capital costs, even large projects, as practice shows, can be reduced. If the project is large, then due to the scale, the cost savings can be significant. 


\section{Results and discussion}

It is necessary to dwell on the key characteristics that should distinguish this model in the subject of research: investments in large infrastructure projects and investments in other types of capital.

First, infrastructure investments are often large capital intensive projects.

Second, they tend to have significant upfront costs, and profits accumulate over very long periods of time, often decades.

Thirdly, there is a difficulty in determining adequate profitability over a long planning horizon, which can become a problem for private financing and project provision.

Fourth, investment in infrastructure generates positive externalities, so the social return of the project may exceed the profit that the construction project generates. For these reasons, large infrastructure projects are projects with state participation, or public-private investors.

For example, the project for the construction of the Central Ring Road in Moscow.

The construction of the Central Ring Road is divided into 5 start-up complexes. For example, the cost of the project for the exit of the 1 st section is from junction 7 to junction 26 is equal to 475028450 RUR., overpass (800 m): 2156895950 RUR. (Fig. 1.):

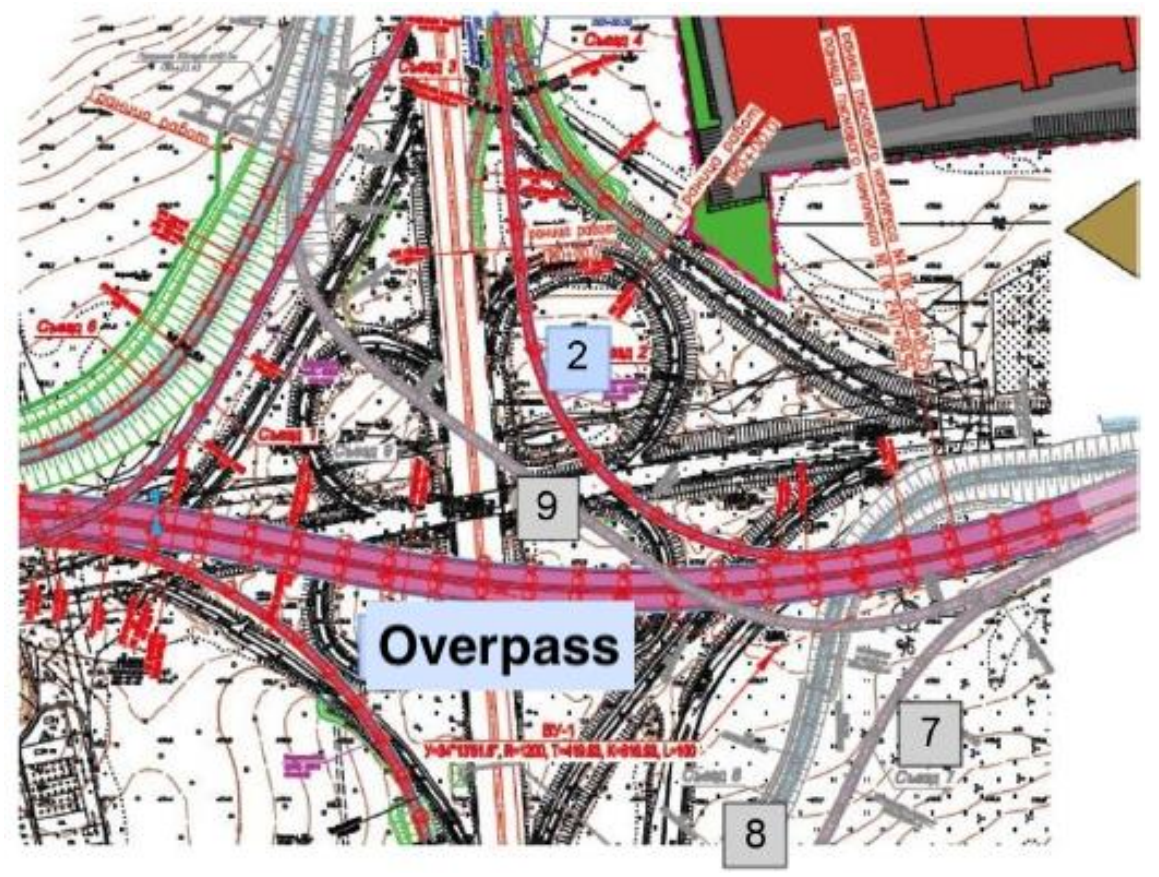

Fig. 1. Central Ring Road, exit 1st section - from junction 7 to junction 26

The technological audit showed that the cost of construction of the 1st section may be lower in some parameters. With an overpass of $800 \mathrm{~m}$, it is possible to reduce the cost of construction on the marking of the carriageway with a thermoplastic line $0.20 \mathrm{~m}$ wide, marking the carriageway with thermoplastic with a line $0.10 \mathrm{~m}$ wide, as well as replacing reinforced concrete pipes with metal corrugated ones (Table 1.). 
Table 1. Reduction of capital costs during the construction of the Central Ring Road, replacement of pipes

\begin{tabular}{|c|c|c|c|c|c|c|}
\hline & \multicolumn{3}{|c|}{ According to design estimates } & \multicolumn{3}{|c|}{ According to TCA Recommendation } \\
\hline Type of material & $\begin{array}{l}\text { Quantity, } \\
\text { r.m. }\end{array}$ & $\begin{array}{l}\text { Unit } \\
\text { prices,Rub. th }\end{array}$ & $\begin{array}{l}\text { Total, } \\
\text { Rub. Th }\end{array}$ & $\begin{array}{l}\text { Number, } \\
\text { run. m. }\end{array}$ & $\begin{array}{l}\text { Unit } \\
\text { prices,Rub. } \\
\text { th }\end{array}$ & $\begin{array}{l}\text { Total, } \\
\text { Rub. Th }\end{array}$ \\
\hline 1 & 2 & 3 & 4 & 5 & 6 & 7 \\
\hline $\begin{array}{l}\text { Round reinforced } \\
\text { concrete culverts } \mathrm{D}= \\
1.5 \mathrm{~m}\end{array}$ & 3890 & 45,95 & 178850 & & & \\
\hline $\begin{array}{l}\text { Round metal corrugated } \\
\text { culverts } \mathrm{D}=1.5 \mathrm{~m}\end{array}$ & & & & 3890 & 40,44 & 157390 \\
\hline \multicolumn{7}{|c|}{ The difference in capital costs -21460 RUB th. } \\
\hline $\begin{array}{l}\text { Rectangular reinforced } \\
\text { concrete culverts otv. } \\
2.0 \times 2.0 \mathrm{~m}\end{array}$ & 362 & 69,85 & 25290 & & & \\
\hline $\begin{array}{l}\text { Round metal-corrugated } \\
\text { culverts } \mathrm{D}=2.5 \mathrm{~m}\end{array}$ & & & & 362 & 79,96 & 28950 \\
\hline
\end{tabular}

Thus, the use of materials of one kind or another, taking into account technological needs, can significantly affect the cost of the project.

The problem in the methodological approaches to evaluating such projects is that with a high social return, the project costs may not be recouped through fees or tax revenues. Such situations require finding a compromise between positive social effects on the one hand and negative fiscal effects on the other.

The economic infrastructure refers primarily to the basic physical assets that directly support the production process. This includes utilities such as electricity and water, transportation networks, communication systems. The assets themselves, and the services they support, provide the necessary resources for the production of other goods and services. Therefore, they play a critical role in the respective supply chains, as well as the broader role that connects producers and consumers and enables the exchange of information and knowledge.

The social infrastructure refers to what can be viewed as public needs such as education, health care, and public services. While they do not directly contribute to the production process, they do play a critical role in protecting and developing the health and skills of the population. They will thus improve the human capital of the nation, which in turn indirectly leads to increased efficiency and productivity in the long run. By providing equal access to public health and education services, social infrastructure improves social cohesion and reduces inequality.

The following coefficients can be proposed as the considered KPI for managing sustainable development of territories in the implementation of construction projects taking into account risks in the reproductive structure of the national economy "(Table 2.): 
Table 2. Coefficients of the dynamics of financial, economic, environmental, social processes for inclusion in the analysis of purchased infrastructure investment projects

\begin{tabular}{|c|c|}
\hline Coefficient & Transcript \\
\hline \multicolumn{2}{|r|}{ Financial appraisal } \\
\hline $\mathrm{k} 1$ & Income-expenses with the project \\
\hline $\mathrm{k} 2$ & IRR \\
\hline $\mathrm{k} 3$ & NPV \\
\hline $\mathrm{k} 4$ & Dynamics of counterfactual expenses \\
\hline $\mathrm{k} 5$ & Dynamics of gross value added \\
\hline \multicolumn{2}{|r|}{ Economic assessment } \\
\hline $\mathrm{k} 8$ & $\begin{array}{l}\text { Accumulating profitability of economic entities } \\
\text { with a project }\end{array}$ \\
\hline k9 & $\begin{array}{l}\text { Accumulating profitability of economic entities } \\
\text { without a project }\end{array}$ \\
\hline $\mathrm{k} 10$ & Environmental impact \\
\hline k11 & Migration effect \\
\hline $\mathrm{k} 12$ & Logistics effect \\
\hline $\mathrm{k} 13$ & GDP dynamics \\
\hline \multicolumn{2}{|r|}{ Social component } \\
\hline k14 & WACC \\
\hline k15 & Product competition \\
\hline k16 & Resource competition \\
\hline k17 & Consumer price dynamics \\
\hline $\mathrm{k} 18$ & Dynamics of educational level \\
\hline k19 & Dynamics of healthcare level \\
\hline
\end{tabular}

Coefficients can change from project to project. In addition to the financial indicators of the project itself, these parameters are needed to assess the most significant macroeconomic indicators.

Infrastructure investments are usually viewed in terms of new projects. However, the significant capital costs associated with maintaining and operating the infrastructure should not be ignored. This is very important, especially in the context of aging infrastructure, as they help to extend the life cycle and slow down capital depreciation, thereby reducing risks to human health.

\subsection{The choice of estimated indicators to determine the effectiveness of an investment project in the reproductive structure of the economy}

The large infrastructure project is always local in nature, since it is located in a certain region, therefore, the assessment of gross value added can be considered by the growth of regional indicators in the economy. According to the methodology for managing large infrastructure investment projects presented in the second chapter, we can determine that the increase in Gross Value Added in the reproductive structure of the economy will equal the sum of gross added incomes by sectors of the economy at the investment and operational stages of the infrastructure project in prices of the base year (3.3.): 


$$
E G V A=\sum_{t=a}^{T}\left[\frac{E G V A n^{t}}{\left(1+r_{j}+\beta\right)^{\left(t-n+x^{12}\right)}}\right] k_{i}
$$

where:

EGVA - the sum of economic effects from the increase in gross value added by sectors of the economy $\mathrm{k}_{\mathrm{i}}$ in year $\mathrm{t}$;

$\mathrm{EVGA}_{n}{ }^{\mathrm{t}}$ - initial gross value added. Includes indicators depending on the project.

$\mathrm{T}$ - the last year of the infrastructure project implementation;

$\mathrm{t}$ - calendar year of the infrastructure project implementation, $\mathrm{t} €[\mathrm{a} ; \mathrm{T}]$;

$\mathrm{a}$ - the first year of the infrastructure project implementation.

$r_{j}$ - the discount rate;

n - years;

$\mathrm{x}^{12}$ is an adjustment value that provides the distribution of discounted cash flows during the year;

$\beta$ - reflects the riskiness of investment in relation to gross value added in the reproductive structure of the economy, can take values from 0.01 to 1 ;

$\mathrm{k}_{\mathrm{i}}$ - coefficient of Gross Value Added of the economic sector of the project being implemented.

An important remark, which was in clause 3.1, even with significant expenditures on the infrastructure project, up to the condition of including the amount of state financing in the state debt, the return on a large infrastructure project may be such that the expenditures in the state debt will overlap with the revenues from the infrastructure project. That is, even government spending will be recouped, and the project will be "self-financing".

\subsection{Algorithm for calculating infrastructure projects}

1. For each of the infrastructure projects, an investment plan with two cash flows is presented: a) with a project; 2) without a project.

The infrastructure project must be calculated with indicators:

- financial evaluation of the model;

- economic evaluation of the model;

- calculation of opportunity costs, "shadow prices";

- economic profitability, taking into account risks, or economic shocks.

2. Free net present value $\left(\mathrm{FNPV}_{1}\right)$, in the case of the "project", is calculated as the difference between the sum of the discounted effects and the sum of the reduced investments

$$
F N P V_{1}=\sum_{t=1}^{T_{r}} K_{1 d}-\sum_{t=1}^{T_{r}} E_{1 d}=\sum_{t=1}^{T_{r}} \frac{K_{1 t}}{(1-r)^{t}}-\sum_{t=1}^{T_{r}} \frac{E_{1 t}}{(1-r)^{t}}
$$

where:

$\mathrm{FNPV}_{1}$ - value of the effect in the t-th year of the billing period Tr, rubles, option "with a project";

$\mathrm{K}_{1 \mathrm{~d}^{-}}$the discounted value of the effect in the $\mathrm{t}$-th year of the billing period $\mathrm{Tr}$, rubles, the "with project" option;

$E_{1 d^{-}}$the discounted value of investments in the $t$-th year of the settlement period $\mathrm{Tr}$, rubles;

$\mathrm{T}_{\mathrm{r}}$ - the duration of the billing period, year;

$t$ - year;

$r$ - discount rate.

3. $\mathrm{FNPV}_{2}$ - calculated similarly, in the case of "no project", the difference between the sum of discounted effects and the sum of the reduced investments is calculated: 


$$
F N P V_{2}=\sum_{t=1}^{T_{r}} K_{2 d}-\sum_{t=1}^{T_{r}} E_{2 d}=\sum_{t=1}^{T_{r}} \frac{K_{2 t}}{(1-r)^{t}}-\sum_{t=1}^{T_{r}} \frac{E_{2 t}}{(1-r)^{t}}
$$

where:

$\mathrm{FNPV}_{2}$ - the size of the effect in the $\mathrm{t}$-th year of the billing period $\mathrm{Tr}$, rubles, the "no project" option;

$\mathrm{K}_{2 \mathrm{~d}}$ - the discounted value of the effect in the $\mathrm{t}$-th year of the billing period $\mathrm{Tr}$, rubles, the "no project" option;

$E_{2 d}$ - the discounted value of investments in the t-th year of the settlement period $\mathrm{Tr}$, rubles, "without a project";

$\mathrm{T}_{\mathrm{r}}$ - the duration of the billing period, year;

$\mathrm{t}$ - year;

$r$ - discount rate.

The internal rate of return (profit) of an infrastructure project (IRR) is the rate at which the amount of reduced income is equal to the amount of reduced investment.

$$
I R R=\sum_{t=1}^{T_{r}} \frac{K_{\mathrm{t}}}{(1+r)^{\mathrm{t}}}-\sum_{t=1}^{T_{r}} \frac{E_{t}}{(1+r)^{\mathrm{t}}}=0
$$

The profitability index of an infrastructure project (I) is the ratio of the amount of reduced income to the amount of reduced investment.

$$
I=\frac{\sum_{\mathrm{t}=1}^{T_{r}} K_{\mathrm{t}}}{\sum_{\mathrm{t}=1}^{\operatorname{Tr}} E_{\mathrm{t}}}
$$

The payback period $\mathrm{T}$ is the period for which the investment is paid off.

4. Calculation of additional free net cash flow from operating activities in the reproduction structure of the economy as a result of the implementation of an infrastructure project.

Since an infrastructure project affects a number of industries and sectors of the economy, it is necessary to introduce general indicators that can be used to determine the added value in the sectors of the economy.

1. The duration of the settlement period $(\mathrm{T})$, year:

$$
T=1+T c
$$

where

1 - the first year of the project;

$\mathrm{T}_{\mathrm{c}}$ - service life of the used object, year.

2. Annual added value for the considered infrastructure facilities before the facility is put into operation (or reconstruction) (Q), rub th.

$$
Q=X * V \kappa l * 12
$$

where

$\mathrm{X}$ - the number of objects, units;

$\mathrm{V}_{\mathrm{k} 1}$ - commercial profitability of the object,

12 - the number of months in a year.

3. Annual added value for the considered infrastructure facilities, after the facility is put into operation (or reconstruction) $\left(\mathrm{V}_{\mathrm{k}}\right)$, rub th. 


$$
V k=V k 1 * k y b
$$

where:

$\mathrm{k}_{\text {ув }}$ - the coefficient of increase in profitability after the commissioning of the infrastructure facility

The indicator levels (low, medium, high, very high) are proposed to be determined based on the dynamics of the average statistical values in the economy as a whole over the past 5 years, based on Rosstat data with a lag of $+/-10 \%$. For example, if GDP decreases in 2020 by 3\%, and in 2019 the indicator of dynamics was + 2\%, then GDP for 2019-2020. decreases by 5\%. Average statistical value of GDP dynamics for 2015-2020 was 7\%. Then the level of dynamics, the ratio $5 / 7=0.71(71 \%)$, will be: $-29 \%$, which is below $10 \%$. This means that the level of the GDP indicator is marked as "low". If the level of dynamics is above $20 \%$, it is marked as "high", if it is above $30 \%$, it is marked as "very high".

Then, comparing several proposed infrastructure investment projects, we get the following table (Table 3.):

Table 3. Results matrix for the considered options for infrastructure projects

\begin{tabular}{|c|l|l|l|l|}
\hline $\begin{array}{c}\text { Project } \\
\text { options }\end{array}$ & $\begin{array}{c}\text { Economic } \\
\text { development }\end{array}$ & Social development & \multicolumn{1}{|c|}{$\begin{array}{c}\text { Infrastructure } \\
\text { communication }\end{array}$} & Ecology \\
\hline 1 & Middle & Very tall & Very tall & Low \\
\hline 2 & Middle & Tall & Tall & Tall \\
\hline 3 & Tall & Tall & Tall & Middle \\
\hline 4 & Very tall & Very tall & Very tall & Very tall \\
\hline 5 & Tall & Tall & Tall & Tall \\
\hline 6 & Middle & Middle & Middle & Middle \\
\hline 7 & Low & Middle & Middle & Middle \\
\hline
\end{tabular}

That will make it possible to determine the economic feasibility of implementing an infrastructure project.

\subsection{Calculation of risks and economic shocks}

Special attention should be paid to the risks and shocks in the economy, which turned out to be the situation in 2020 with COVID-19.

We calculate risks taking into account the assessment of incurred (or potential) costs, taking into account discounting, using the following formula:

$$
L_{k}=\sum_{r=0}^{R t} \frac{L_{k r}}{(1+t)^{r}} .
$$

where:

$(1+\mathrm{t}) \mathrm{r}$ - discount rate;

$\mathrm{L}_{\mathrm{k}}$ - the life cycle of the total costs of eliminating the consequences of events;

$\mathrm{T}$ - the year.

Having simulated force majeure (shock) periods, under force majeure circumstances, when the impact on a construction infrastructure project in the area of damage is huge in a 
short period of time, it is possible to determine only the dynamics of losses incurred in monetary terms, depending on identification factors.

It is possible to determine the correlation dependence of the influencing factors on the result only approximately, since the studied series of changes do not contain a definite trend.

Therefore, the total costs incurred during the shock period in the management of the infrastructure project will be taken as the sum of direct and indirect costs.

Full costs are determined at a specific point in time and are intermediate, compared to the total damage, which will be quantified in the long term in the event of economic shocks.

The need to consider distributed in time or remote manifestations of force majeure is important for infrastructure projects in a long life cycle, since the period of such shocks can last 5,10 or more years, up to a significant reconstruction of the object.

The total economic costs, which can result in force majeure circumstances, we will define as the sum of direct economic costs (for example, as a result of falling prices for materials, etc.) and indirect economic costs (for example, due to a decrease in the effective demand of the population and how the result, not the payback of the expressway).

Total economic costs are calculated as the sum of direct and indirect costs and are calculated using the formula:

$$
L f=L r+L k,
$$

$\mathrm{L}_{\mathrm{f}}$ - the total economic costs of the shock period;

$\mathrm{L}_{\mathrm{r}}$ - direct costs of the shock period

$\mathrm{L}_{\mathrm{k}}$ - indirect costs of the shock period.

At the same time, it should be borne in mind that the differentiation of costs for direct and indirect during the shock period is to some extent conditional, especially with regard to indirect costs, since the same losses can be mediated in different sectors of the economy.

Thus, a number of tools that are presented above can be involved in determining the effectiveness of the implementation of large infrastructure projects. The main difference in the choice of tools when calculating a large infrastructure project is the assessment of the social component of the project, which, as we have shown, in the future may develop into a sufficiently large economic effect in the reproduction of the added value of both the regional economy and the Russian economy as a whole.

\section{Conclusion}

The peculiarity of methodological approaches to assessing large infrastructure projects in the sustainable development of territories is that with a high social return, project costs may not be recouped by fees or tax revenues. Such situations require a trade-off between positive social effects and negative fiscal effects. At the same time, the sustainability of the development of territories due to large construction projects in the reproductive structure of the economy is associated with an increase in investment in public infrastructure and affects the economy in two ways: 1) in the short term - the project increases aggregate demand through short-term fiscal multipliers; 2) public investments increase the stocks of public debt if the state borrows, but the infrastructure project pays for it.

The methodology for managing sustainable development of territories through the reproduction structure of large investment construction projects should take into account the key importance of determining how large the side effect of production growth will be in various economic sectors. The conditions for managing large infrastructure projects were formulated: 1) relying on a simple distinction between primary and secondary markets, we establish the conditions under which the inclusion of project impacts on the secondary 
market is more valid; 2) the concepts of broader economic consequences are investigated, especially on the reproduction of the economy; 3) some changes in the assessment of profitability in the context of transport projects are investigated; 4) broader economic impact refers to the impact of investments in the primary market and the secondary market.

As a result, the sustainable development of territories manifests itself through the profitability of the infrastructure project and is not measured only by the total revenues or project costs for stakeholders, but is measured by additional, or increasing revenues and costs caused in excess of the project after its implementation. Sustainability, in this case, should be determined in comparison: the project is being implemented, or the project is not being implemented.

\section{References}

1. L.N. Moses, Journal of Economics, 78, 259 (1958).

2. W. Alonso, Harvard University Press (1964).

3. E.L. Stupnikova, Journal of Transport construction,7, 23 (2011)

4. M.M. Fujita, J.F. Thisse, Cambridge University Press (2002)

5. A.V. Sorokina, Moscow State Transport University (2011)

6. M.J. Melitz, G.I.P. Ottaviano, The Review of Economic Studies, 75, 295 (2008)

7. M.M. Gerasimov, O.A.Olenina, E.A.Stupnikova., P.E. Tsypin, MIIT, 178 (2012)

8. R.L. Moomaw, J.K. Mullen, M. Williams, Southern Economic Journal, 61, 830 (1995)

9. European Commission: Transport White Paper,144 (2011)

10. A.V. Babanov, Russian State Humanitarian Journal University,4 , 107 (2012)

11. L.E. Basovskiy, E.N. Basovskaya, INFRA-M (2008)

12. G.Z. Gabidullina, Science (2013)

13. S.V. Aleksikov, Monograph, 208 (2006)

14. D. Aschauer, Journal of Monetary Economics, 23(2), 177 (1989)

15. E.L. Stupnikova, A.I. Sadykov, Journal of The development of economic science in the trnasoprt, 745 (2019)

16. P. Krugman, ForeignAffairs, 73(2), 28 (1994)

17. G.N. Zhinkin, PGUPS, (1996)

18. T. Litman, Victoria Transport Policy Institute (2012)

19. O. Ivanova, Ch. Heindricks, K. Spitaels, T. Tavassi, W. Manshanden, M.Snelder and O. Coops, RAEM: version 3.0 (2007)

20. A.V. Babanov, Bulletin of the EMA. 2, 174 (2012)

21. W. Schade, C. Doll, M. Maibach, M. Peter, F. Crespo, D. Carvalho, G. Caiado, M. Conti, A. Lilico, N. Afraz,Funded by European Commission (2006)

22. G.Z. Gabidullina, Science (2013)

23. E.B. Nikolenko, Science (2012)

24. G. Jong, A.J. de, DalyM. Pieters \& A.I.J.M. van der Hoorn, Vrije Universiteit Amsterdam (2005)

25. Resolution of the Government of the Russian Federation of November 26, 1512 (2019) 